\title{
Screening for over 1000 organic micropollutants in surface water and sediments in the Liaohe River watershed
}

\author{
Qingwei Bu ${ }^{\mathrm{a}, \mathrm{c}, \mathrm{d}}$, Qian Luo ${ }^{\mathrm{b}}$, Donghong Wang ${ }^{\mathrm{b}, *}$, Kaifeng Rao ${ }^{\mathrm{c}}$, Zijian Wang ${ }^{\mathrm{c}}$, Gang Yu ${ }^{\mathrm{d}}$ \\ ${ }^{a}$ School of Chemical E Environmental Engineering, China University of Mining E Technology-Beijing, Beijing 100083, China \\ ${ }^{\mathrm{b}}$ Key Laboratory of Drinking Water Science and Technology, Research Center for Eco-Environmental Sciences, Chinese Academy of Sciences, P.O. Box 2871, Beijing 100085, China \\ ' State Key Laboratory of Environmental Aquatic Chemistry, Research Center for Eco-Environmental Sciences, Chinese Academy of Sciences, P.O. Box 2871, Beijing 100085, China \\ ${ }^{\mathrm{d}}$ School of Environment, POPs Research Center, State Key Joint Laboratory of Environment Simulation and Pollution Control, Tsinghua University, Beijing 100084, China
}

\section{H I G H L I G H T S}

- The reliability and usefulness of high throughout screening method was evaluated.

- The massive qualitative data help unveil pollution profiles among different sites.

- The semi-quantification results agree well with those from target analysis.

- The high throughout method is proven be a valuable tool in watershed management.

\section{A R T I C L E I N F O}

\section{Article history:}

Received 5 April 2015

Received in revised form 16 June 2015

Accepted 6 July 2015

Available online 21 July 2015

\section{Keywords:}

Semi-quantification

Screening analysis

Source identification

Watershed management

Cluster analysis

\begin{abstract}
A B S T R A C T
High throughout screening method has gained attractive prospects because it offers a fast and effective approach to obtain a holistic picture of organic micropollutant $(\mathrm{OM})$ pollution in a site specific environment. However, reliability and usefulness of the generated data sets for OM pollution profiles and occurrence levels have not been fully evaluated. In this paper, we screened 1030 OMs in surface water and sediments from the selected rivers of the Liaohe River watershed to (1) examine the usefulness of using qualitative data to gain insights into source identification and (2) further evaluate the reliability of the semi-quantification results in a filed study. The results showed that 81 and 89 OMs at concentrations up to $5670 \mathrm{ng} / \mathrm{L}$ and $6714 \mathrm{ng} / \mathrm{g}$ were identified in surface water and sediments, respectively. Qualitative data could be used to identify the similarity (or dissimilarity) of pollution sources at different locations for surface water, which could provide insights for source back tracking of water contamination. Accuracy tests showed that our semi-quantification results agree well with those from previously reported values and our target analysis. Though our results for the majority of newly quantified OMs need to be further confirmed, we have demonstrated that this method is suitable for understanding the pollution characteristics and occurrence levels of OMs in the environment for environmental scientists and managers.
\end{abstract}

(c) 2015 Elsevier Ltd. All rights reserved.

\section{Introduction}

Thousands of organic chemicals have been produced and released into the aquatic environment, and new chemicals are being continuously introduced (Bu et al., 2013a). Some of these contaminants pose risks to human health and/or the environment even at extremely low concentrations [known as organic micropollutants (OMs)] (Feron et al., 2002; Long et al., 1995; Sharpe, 2001; Sharpe and Irvine, 2004). Due to the increasing sensitivity of

\footnotetext{
* Corresponding author.

E-mail address: dhwang@rcees.ac.cn (D. Wang).
}

analytical methods, the number of OMs detected in the aquatic environment is on the rise over the past decade (Schwarzenbach et al., 2010). However, our knowledge of OM contamination levels in the aquatic environment is still limited because only a small fraction of OMs can be probed by the vast majority of traditional target analysis. The target analysis used to assess OM contamination levels usually covers few compounds and is time-consuming and costly. Alternatively, methods that fulfill the goal of high throughout screening of OMs in environmental samples are gaining attractive prospects for environmental scientists and managers, because the screening method could analyze several hundreds or even more OMs simultaneously. 
Several methods for screening organic micropollutants in the aquatic environment have been reported (Gómez et al., 2009; Kadokami et al., 2012, 2005) and are proven to be useful for screening environmental samples (Duong et al., 2014; Kadokami et al., 2013; Pan et al., 2014). In our previous study, a method for screening 50 phenols in water was established and applied in the case of Taihu Lake (Zhong et al., 2010). Further, this method was modified for qualitative screening of 1093 OMs in water of the Danjiangkou reservoir (Bu et al., 2014a). More recently, we introduced a set of quantification internal standards (QISs) to improve the quantification ability of the method, and results showed that the high throughout semi-quantification method was feasible for comprehensive analysis of OMs in sediments quantitatively (Bu et al., 2014b). The high throughout screening analysis could produce a database comprising of a large pool of both qualitative and quantitative data of contaminants, which can help understand the pollution characteristic and occurrence level of OMs in the investigated sites. However, usefulness and reliability of the data sets generated from the high throughout method have not been fully demonstrated.

One of our goals is to examine the usefulness of using qualitative data to gain insights into source identification. Generally, pollution characteristics of sampling sites are related to the source types, especially the point source types at a local scale. The hypothesis is that the acquired qualitative data could be used to differentiate pollution characteristics of different sites, and further to offer a basis for source identification. Here we did not aim to identify emission sources for individual OMs and their contribution to each sampling site, because our straight goal is focused on how to get the maximum use of qualitative data to identify similarity (or dissimilarity) of pollution sources for different locations. Another goal of this work is to further evaluate the reliability of the semi-quantification results in a field study. To this end, quantitative data generated from this semi-quantification method was compared to those obtained by target analysis. To accomplish these goals, we reported an application of our previously proposed high throughout semi-quantification method (Bu et al., 2014b) for screening OMs in surface water and sediments from selected rivers of the Liaohe River watershed.

\section{Materials \& methods}

\subsection{Chemicals and materials}

All solvents (including methanol, acetone, dichloromethane, $n$-hexane) were HPLC grade (J.T Baker, Phillipsburg, NJ, USA). All standards were purchased from AccuStandard Inc. (New Haven, Connecticut, USA). All glassware was washed with acetone and water, soaked overnight in concentrated sulfuric acid containing $5 \% \mathrm{~K}_{2} \mathrm{Cr}_{2} \mathrm{O}_{4}$ solution, and baked at $550-600{ }^{\circ} \mathrm{C}$ for five hours after washing with ultra-pure water.

\subsection{Study sites and sampling}

Liaohe River watershed is located in the Northeastern China and originates from the Qilaotu Mountain, runs about $1345 \mathrm{~km}$ into Liaodong Bay, covering an area of $191,900 \mathrm{~km}^{2}$. A large number of municipal and industrial facilities are located in the catchment, especially in the lower reaches in Liaoning Province, which is one of the most heavily polluted regions in China. Therefore, four main streams in Liaoning Province including Liaohe River, Hunhe River, Taizihe River, and Daliaohe River provide an ideal setting to explore the goals of this work (Fig. S1). Based on the goal of evaluating the usefulness of qualitative data in source identification, twelve national monitoring cross-sections which accept various types of sewages, were selected (Table 1). At each section, surface water and respective sediment samples were collected in April 2011 along the riverside. At each sampling site, surface water (0$20 \mathrm{~cm}$ depth, $>2 \mathrm{~L}$ ) was collected by a stainless sampler ( $5 \mathrm{~L}$ ) and filtered using Millipore glass microfiber filters $(0.7 \mu \mathrm{m}$, Millipore, USA) immediately. After that, they were preserved in amber glass bottles at $4{ }^{\circ} \mathrm{C}$ until analysis. Surficial river sediment samples (0$10 \mathrm{~cm}$ depth) were collected using a grab sampler $(15 \times 15 \mathrm{~cm})$ and immediately transported to the laboratory and stored at $-20^{\circ} \mathrm{C}$.

\subsection{Sample pretreatment}

The analytical procedures for surface water samples were performed according to Bu et al. (2014a) and Zhong et al. (2010). Briefly, two liter of water was extracted by solid phase extraction with C18 (500 mg, $6 \mathrm{ml}$; Supelco, Bellefonte, PA, USA) coupled with Oasis ${ }^{\circledR}$ hydrophilic-lipophilic balance (HLB, $500 \mathrm{mg}, 6 \mathrm{ml}$; Waters, Milford, MA, USA) cartridges. The cartridges were eluted by $10 \mathrm{ml}$ of dichloromethane. The extract was concentrated under a gentle stream of nitrogen and thereafter, the solvent was changed from dichloromethane to hexane $(0.5 \mathrm{ml})$ for instrumental analysis.

OMs in the sediment were analyzed using the method of $\mathrm{Bu}$ et al. (2014b). In short, the freeze-dried sediment $(5 \mathrm{~g})$ was extracted with dichloromethane/acetone $(1: 1, v / v)$ using an accelerated solvent extraction system (Dionex ASE350, Dionex, Sunnyvale, California, SA). The extract was cleaned-up by the gel permeation chromatography (GPC) equipped with a Bio-Beads SX3 column (Bio-Rad Laboratories, Hercules, California, USA) using cyclohexane/ethyl acetate $(1: 1, v / v)$ as mobile phase. Thereafter, the solvent as changed to hexane in approximately $1 \mathrm{ml}$ under a gentle stream of highly pure nitrogen. The hexane concentrate was applied to a Florisil (500 mg, $6 \mathrm{ml}$; Supelco, Bellefonte, PA, USA) cartridge for further cleanup process. The cartridge was eluted by $5 \mathrm{ml}$ of mixture of dichloromethane/acetone $(1: 1, \mathrm{v} / \mathrm{v})$. The solution of the cleaned extract was changed to hexane $(0.2 \mathrm{ml})$ before instrumental analysis.

\subsection{Instrumental analysis and semi-quatification}

The sample analysis was carried out using an Agilent 6890N-5975D gas chromatography-mass selective detector (GCMSD; Agilent Technologies, Santa Clara, California, USA) equipped with a DB-5 ms capillary column $(30 \mathrm{~m} \times 0.25 \mathrm{~mm}$ i.d. $\times 0.25 \mu \mathrm{m}$ film thickness, J\&W Scientific, USA). High purity helium (99.9999\%) was used as the carrier gas. Data acquisition and processing were based on retention time locking and deconvolution technologies, which was accessed in ChemStation Software (version E.0200.493; Agilent Technologies, USA). One complete run lasted $48 \mathrm{~min}$, details of the GC-MSD method was described in previous studies (Bu et al., 2014b; Bu et al., 2014a).

The database used for screening analysis included 1030 OMs as that in Wylie (2006) and Quimby and Szelewski (2006), which are also listed in detail in Table S1. Deconvolution was run to identify OMs according to the following two criteria: the automated mass spectral deconvolution and identification system match values were higher than $60 \%$; the expected retention time value differed from the observed one in less than $10 \mathrm{~s}$. The extracted spectrum was also reverse-matched with the National Institute of Standards and Technology library to further confirm the positive identification. For semi-quantification, the 1030 OMs were categorized into 15 groups according to their chemical classes, and for each class a QIS was assigned (Table S1). Then quantification was conducted by comparing the peak area of identified OM to the respective QIS assigned by its chemical classes. The method 
Table 1

Description of the 12 national monitoring cross-sections from the four rivers in Liaohe River watershed in Liaoning Province.

\begin{tabular}{|c|c|c|c|c|c|}
\hline River & Site & City & Location & & Sewage types discharged into rivers \\
\hline Liaohe River & $\begin{array}{l}\text { S1 } \\
\text { S2 } \\
\text { S7 }\end{array}$ & $\begin{array}{l}\text { Tieling } \\
\text { Shenyang } \\
\text { Panjin }\end{array}$ & $\begin{array}{l}42^{\circ} 36^{\prime} 51.70^{\prime \prime} \mathrm{N} \\
41^{\circ} 27^{\prime} 20.84^{\prime \prime} \mathrm{N} \\
41^{\circ} 7^{\prime} 28.31^{\prime \prime} \mathrm{N}\end{array}$ & $\begin{array}{l}123^{\circ} 39^{\prime} 8.60^{\prime \prime} \mathrm{E} \\
122^{\circ} 37^{\prime} 30.89^{\prime \prime} \mathrm{E} \\
121^{\circ} 54^{\prime} 12.39^{\prime \prime} \mathrm{E}\end{array}$ & $\begin{array}{l}\mathrm{D}+\mathrm{I}(\text { (unknown })^{\mathrm{b}} \\
\mathrm{D}+\mathrm{I}(\text { unknown })^{\mathrm{b}} \\
\mathrm{D}+\mathrm{I}(\text { (Oil exploration) }\end{array}$ \\
\hline Hunhe River & $\begin{array}{l}\text { S3 } \\
\text { S4 } \\
\text { S5 } \\
\text { S6 }\end{array}$ & $\begin{array}{l}\text { Fushun } \\
\text { Fushun } \\
\text { Fushun } \\
\text { Shenyang }\end{array}$ & $\begin{array}{l}41^{\circ} 58^{\prime} 39.20^{\prime \prime} \mathrm{N} \\
41^{\circ} 53^{\prime} 18.75^{\prime \prime} \mathrm{N} \\
41^{\circ} 49^{\prime} 54.59^{\prime \prime} \mathrm{N} \\
41^{\circ} 14^{\prime} 38.43^{\prime \prime} \mathrm{N}\end{array}$ & $\begin{array}{l}124^{\circ} 22^{\prime} 52.31^{\prime \prime} \mathrm{E} \\
124^{\circ} 6^{\prime} 7.84^{\prime \prime} \mathrm{E} \\
123^{\circ} 40^{\prime} 2.34^{\prime \prime} \mathrm{E} \\
122^{\circ} 39^{\prime} 46.68^{\prime \prime} \mathrm{E}\end{array}$ & $\begin{array}{l}\text { None }^{c} \\
\text { None }^{c} \\
\text { I (Petrochemical) } \\
\text { D }\end{array}$ \\
\hline Taizihe River & $\begin{array}{l}\text { S8 } \\
\text { S9 } \\
\text { S10 } \\
\text { S11 }\end{array}$ & $\begin{array}{l}\text { Benxi } \\
\text { Benxi } \\
\text { Liaoyang } \\
\text { Anshan }\end{array}$ & $\begin{array}{l}41^{\circ} 22^{\prime} 33.43^{\prime \prime} \mathrm{N} \\
41^{\circ} 16^{\prime} 23.44^{\prime \prime} \mathrm{N} \\
41^{\circ} 10^{\prime} 44.25^{\prime \prime} \mathrm{N} \\
41^{\circ} 0^{\prime} 2.35^{\prime \prime} \mathrm{N}\end{array}$ & $\begin{array}{l}123^{\circ} 53^{\prime} 37.59^{\prime \prime} \mathrm{E} \\
123^{\circ} 42^{\prime} 2.32^{\prime \prime} \mathrm{E} \\
122^{\circ} 42^{\prime} 31.37^{\prime \prime} \mathrm{E} \\
122^{\circ} 29^{\prime} 56.25^{\prime \prime} \mathrm{E}\end{array}$ & $\begin{array}{l}\text { None c } \\
\text { I (Steel) } \\
\text { I (Printing and dyeing) } \\
\text { I (Mining) }\end{array}$ \\
\hline Daliaohe River & S12 & Yingkou & $41^{\circ} 0^{\prime} 20.03^{\prime \prime} \mathrm{N}$ & $122^{\circ} 24^{\prime} 47.97^{\prime \prime} \mathrm{E}$ & $\mathrm{D}$ \\
\hline
\end{tabular}

a D and I stand for domestic and industrial sewages, respectively.

b The proportion of domestic (or industrial) sewage is not available.

c Discharge of sewage was prohibited to the source water.

detection limit (MDL) for the substances was estimated from concentration ratio (or, ratio of the dry weight of sediment to the volume of final concentrate) and the instrumental detection limit of scan calculated according to the respective QIS (Table S1). For $85 \%$ of the OMs in the database, The MDLs were $\leqslant 2 \mu \mathrm{g} / \mathrm{kg}$ and $\leqslant 12.5 \mathrm{ng} / \mathrm{L}$ for sediment and surface water, respectively.

\subsection{Quality control}

Quality controls were done by overall recovery tests and blank control experiments during sample analysis. For sediments, recovery tests were carried out using 57 model OMs spiked at two concentration levels. The model OMs cover a wide range of physio-chemical properties. As a result, the method performed well to analyze most of OMs, except for the volatile (e.g. naphthalene), the thermal sensitive ones (e.g. chlorfenvinphos) and the polar OMs (e.g. dichlorvos). For surface water, one spiked sample containing 41 model OMs was analyzed using the same procedure as that for real samples. The results showed that the method can quantitatively analyze most OMs in surface water. Detailed recovery rates for the quality control samples were listed in Tables S2 and S3. Recovery rates were obtained by comparing the peak area of each detected model OM to the respective standard. Reported semi-quantification concentrations were not corrected for recovery values. Method blank control samples were carried out for every batch of six samples and no OM was introduced during sample pretreat and determination procedures.

\subsection{Analysis of total organic carbon (TOC)}

TOC in the sediment was measured by a WR112 LECO carbon detector (LECO Corp., Michigan, USA) and expressed as a percentage of sediment dry weight.

\subsection{Statistical analyses}

The massive data obtained from the high throughout screening analysis was managed and processed by using Microsoft Excel 2010 (Microsoft China, Beijing, China). The statistical analysis was performed using SPSS software package (version 13.0, SPSS Inc., Chicago, IL, USA). The Monte Carlo simulation was performed by using Crystal Ball software (Student Edition).

\section{Results and discussion}

\subsection{Usefulness of qualitative data}

\subsubsection{Overview}

Detailed screening results for surface water were summarized in Table S4. The number of identified OMs at each sampling site varied from 14 individual chemicals at S3 (source water) to 38 individual chemicals at S12. A total of 81 OMs belonging to 23 chemical classes were identified at least once in surface water, 18 of which were detected at frequencies over $50 \%$. This number of detection was larger than those (46 OMs in 17 chemical classes) detected in the Danjiangkou reservoir using the same method (Bu et al., 2014a), as the Danjiangkou reservoir was designated as a drinking water source by strict protection. Great variety of OMs was identified from samples extracted from sampling sites, including pesticides and their metabolites, intermediates in organic synthesis, pharmaceuticals and personal care products. In the sight of use types, most of them ( 45 out of 81 ) were related to industrial activities, which are in accordance with the fact that the Liaohe River watershed was one of the most important industrial bases in Northeastern China. These OMs were mainly intermediates used by the industries that appear to have discharged industrial wastewater effluents to rivers. In the meantime, 25 out of the 81 identified OMs were pesticides and their metabolites that are indicative of the intensive agricultural activities in the studied area.

As for sediments, the detailed screening results for the 12 sites were summarized in Table S5. The number of detected OMs ranged from 18 at site S1 to 52 individual OMs at site S5. In general, greater number of OMs was detected at sites with higher TOC in sediments, as OMs are prone to accumulate in the organic carbon-rich phase. Eighty-nine OMs in 23 chemical classes were detected at least once, nearly 30 OMs occurred at more than half of the sampling sites. This number of detection was comparable to those (70 OMs) identified in 24 sediments of the Haihe River watershed (Bu et al., 2014b). It is also observed that the OMs detected in sediments are from diverse chemical classes, and they were similar in use types related to industrial and agricultural activities. In short, 89 identified OMs consist of 25 pesticides, 49 industrial chemicals and 15 household related substances (Table S5).

\subsubsection{Evaluation of the usefulness of qualitative data}

The qualitative data can be expressed as binary data indicated as detection and non-detection of OMs at each sampling site, 
which could be utilized to characterize pollution profiles of the sampling sites. To explore the usefulness of qualitative data in identifying similarity (or dissimilarity) of pollution sources for different locations, a hierarchical cluster analysis was performed to classify the 12 sites. The results indicated clear differences between sampling sites (Fig. 1a). Sites S3, S4 and S8 were recognized as a separate group, indicating comparable pollution profiles or characteristics. Hence it is inferred that these three sites may have similar pollution sources. From the description of sampling sites (Table 1) it is found that they are drinking water-source locations that undergo strict pollution control. Meantime, other cluster results also support this. For example, a second group composed of sites S6 and S12 was created due to the similar pollution characteristics indicated by qualitative data. And it can be noted that both sites only accept domestic wastewater as main pollution sources (Table 1). In addition, sites S5 and S9 were grouped together as the result of industrial effluents, although they are geographically far away from each other (Table 1 and Fig. S1). These results demonstrated that by analyzing qualitative data, environmental water samples that have similar sources could be clustered together and that have different sources could be differentiated.

Distinct from surface water, however, pollution profile of OMs in sediments may shift dramatically as the OM re-distribution between water and sediment is affected by both environmental characteristics (e.g. TOC) and the characteristics of contaminants (Schwarzenbach et al., 2003). As the result binary hierarchical cluster analysis was used to classify the 12 sediments samples of different characteristics. We found that different groups were formed, which is in striking contrast to surface water (Fig. 1a and b). Pollution characteristics of OMs at sites S3 and S8 were identical for surface water, while quite distinct for sediments. Similar findings were noted at sites S5 and S9, and sites S10 and S11. These results could be partly explained by the different characteristics of sediments (e.g. TOC) between sampling sites. For instance, significantly higher TOC in sediment was observed at site S5 $(3.15 \%)$ than S9 (1.04\%) (Table S6).This indicates that OMs are readily adsorbed on sediment at site $\mathrm{S} 5$. As a result, pollution profiles of OMs in sediments at sites S5 and S9 were drastically different. For sediments, sites S8, S9 and S4 formed a cluster. Pollution profiles of OMs in surface water at sites S8 and S4 were similar (Fig. 1a), while they were a little further away from each other. Pollution profile of OMs in sediment of S9 was even closer to those at S4 and S8, however, site S9 accepted wastewater from the steel industry and sites S4 and S8 were drinking water sources (Table 1). This 'shift' could be attributed to the re-distribution of OMs

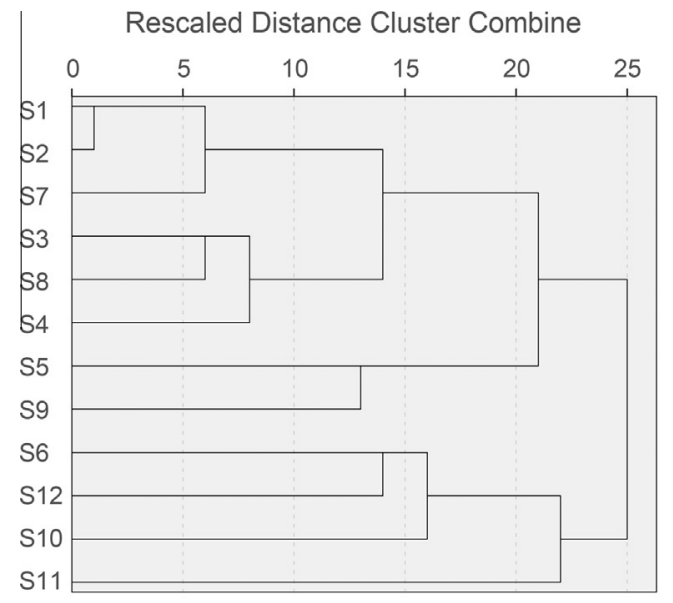

(a) water between water and sediment. Sites S6, S11 and S12 were identified as a separate group as they were clustered together in the analysis for surface water, due to the same wastewater type they accepted. Sites S3, S10 and S7 were clustered to a group. As we stated above, $\mathrm{S} 3$ was protected to use for drinking water and has a limited detection of OMs. S10 and S7, where domestic and industrial wastewater, were heavily polluted in surface water. However, sediments at these sites seem to be as clean (less OMs detected) as S3. This is due to the lower TOC in sediments of these two sites (Table S6) that less OMs could accumulate in.

From the above discussion, it can be concluded from the above discussion that it is effective to use qualitative data to identify the similarity (or dissimilarity) of pollution sources for different locations for water phase, while for sediment phase it can successfully grasp the shift of pollution characteristics from water to sediment.

Identification of pollution sources for environmental sites is a complex work that needs a large pool of information. Researchers have demonstrated the usefulness of using quantitative data for source identification [e.g. Pan et al. (2014), Duong et al. (2014), Bu et al. (2009)]. However, qualitative data could usually be easily obtained than quantitative ones, especially in the high throughout screening analysis. As more and more contaminants being included into the screening database, it can be expected the qualitative data would show a greater potential in understanding pollution characteristics and sources of environmental samples. Though this work demonstrated that it is possible to gain insights into source identification by analyzing qualitative data for water phase, it should be noted that we only made a simple connection between source-to-sink relationships in the present study to verify the usefulness of qualitative data in source identification in water phase. In the future application, obtained qualitative data only tell which sites have the same source. But it cannot tell what the specific source is. Therefore, our next work could be constructing a database characterizing the pollution profiles of different sources (e.g. wastewater of different types). With this knowledge, pollution profiles of environmental water could be compared to those for wastewater, and it can be expected that any unknown sample could be back-traced to known sources (e.g. wastewater) by a discrimination analysis.

\subsection{Reliability of quantification results}

Semi-quantification offered a convenient approach to quantify the $\mathrm{OM}$ concentrations in the preliminary screening analysis. However, the accuracy of the quantification results should be fully Rescaled Distance Cluster Combine

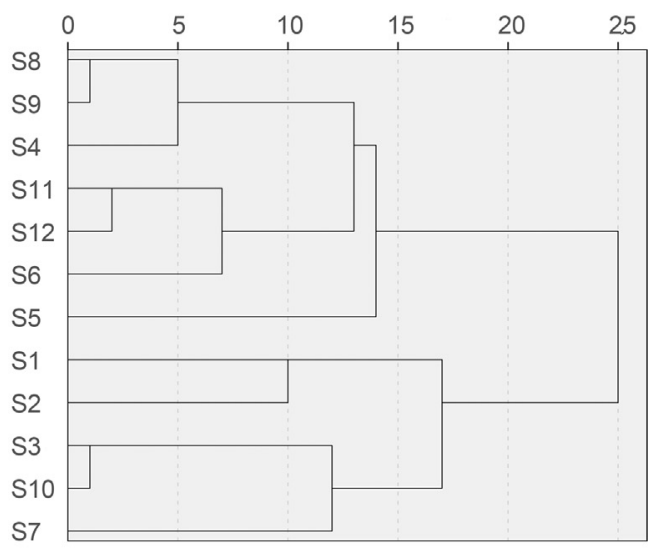

(b) sediment

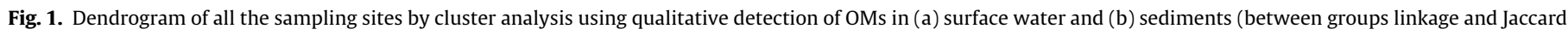
measure). 


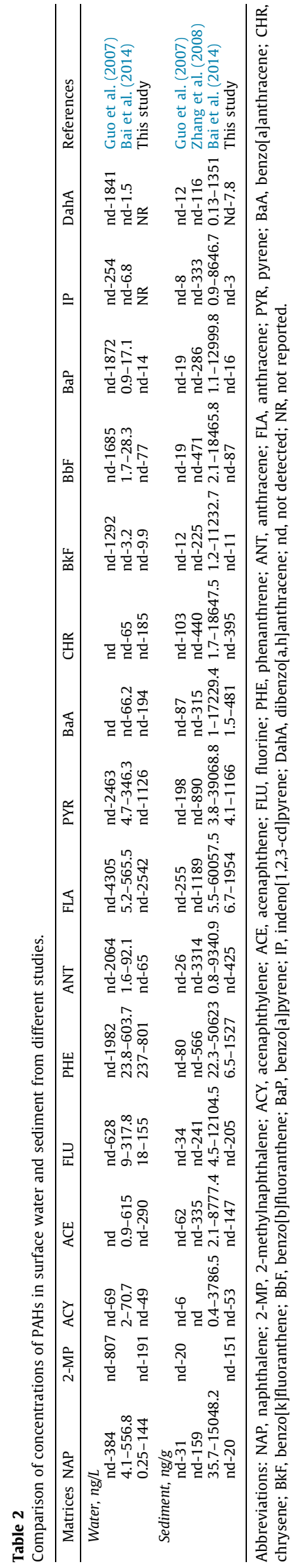

evaluated and explained in caution. In our previous study, accuracy of the quantification was tested by comparing with the spiked solutions. Our results showed that the calculated concentrations deviated from measured values by a factor of 4 for most OMs (Bu et al., 2014b). The goal of the present study is thus to accurately determine the accuracy of our quantification method by comparing with the results of field studies.

\subsubsection{Overview}

Detailed results were listed in Tables S4 and S5. OM concentrations ranged from not detected (nd) to $5670 \mathrm{ng} / \mathrm{L}$ and nd to $6714 \mathrm{ng} / \mathrm{g}$ in surface water and sediment, respectively. A total of 170 OMs were detected in surface water and sediments, with 49 being detected in both compartments (Tables S4 and S5).

\subsubsection{OMs reported before}

Of the 121 detected individual OMs, only 21 were reported in surface water or sediments before (Tables S4 and S5). They were mainly polycyclic aromatic hydrocarbons (PAHs), pesticides, and a chemical (i.e. triclosan) used in personal care products.

PAH levels in the surface water in this study were similar to those determined by Bai et al. (2014), but generally several times lower than a previous report (Guo et al., 2007) (Table 2). In contrast, it can be found from Table 2 that our results for PAH concentrations in sediments were comparable to those reported by Guo et al. (2007), but slightly lower than those by Zhang et al. (2008), and much lower than those in Bai et al. (2014).

We also conducted a target analysis for PAHs in water and sediments of selected sampling sites using a traditional target analytical method described in Qiao et al. (2008). The detailed results are listed in Tables S7 and S8. It can be found that our semi-quantification results were usually higher by a factor of 5 or more than those from target analysis for most PAHs in either surface water or sediments. This difference can be partly attributed to the different response factors between PAHs and their semi-quantification internal standards on MSD. Another reason for this may be the matrix enhancement effects due to the clean-up method used in the high throughout screening method is designed for all contaminants, which would introduce more interfering materials for GC-MSD analysis.

Only four pesticides were identified from previously published studies in the Liaohe River watershed. The quantification results for pesticides usually agreed well with those reported values from different studies (Table 3), at concentrations from nd to several $\mathrm{ng} / \mathrm{L}$ and nd to several ng/g in surface water and sediments, respectively. A PPCP, triclosan, was identified before as we found in the present study. Our reported values were usually lower by one order of magnitude than those in the previously reported literature, either for surface water or sediment (Table 3 ). The variation observed between studies may result from the deviation in sampling locations, periods, etc. Hence from the point of accuracy evaluation, the semi-quantification method performed well and it can be concluded that the semi-quantification results are accurate enough for preliminary screening analysis.

\subsubsection{OMs unreported before}

Of the 121 OMs detected, 100 were unreported before and a validation of the accuracy in the field way is not possible at present because existing study is unavailable for the Liaohe river watershed. If possible, target analysis should be conducted to verify their occurrence levels, especially for OMs with high occurring frequency in multi-media (e.g. terbucarb, Tables S4 and S5). Terbucarb is a frequently detected contaminant in China in our previous studies for sediments in Haihe River watershed ( $\mathrm{Bu}$ et al., 2014b) and surface water in Danjiangkou reservoir (Bu et al., 2014a). Terbucarb is used as an insecticide and an herbicide 
Table 3

Comparison of concentrations of pesticides and triclosan in surface water and sediment from different studies.

\begin{tabular}{|c|c|c|c|c|c|c|}
\hline Matrices & Atrazine & Prometryn & Simetryn & $4,4^{\prime}$-DDT & Triclosan & References \\
\hline \multicolumn{7}{|c|}{ Water, $n g / L$} \\
\hline & $4520-17500$ & & & & & Yan et al. (2005) \\
\hline & $77-204^{a}$ & & & & & Gfrerer et al. (2002) \\
\hline & $66-1513^{b}$ & nd-6.4 & nd-10.7 & & & Gfrerer et al. (2002) \\
\hline & & & & & $2.4-404$ & Zhao et al. (2013) \\
\hline & nd-1525 & nd-18 & nd-32 & NR & nd-7.7 & This study \\
\hline \multicolumn{7}{|c|}{ Sediment, ng/g } \\
\hline & nd $-2.8^{\mathrm{b}}$ & & & & & Gfrerer et al. (2002) \\
\hline & & & & nd-0.61 & & Wang et al. (2007) \\
\hline & & & & & nd-40 & Zhao et al. (2013) \\
\hline & NR & NR & NR & nd-3.3 & nd-3.5 & This study \\
\hline
\end{tabular}

Abbreviations: nd, not detected; NR, not reported.

a Sampling year $=1998$.

b Sampling year $=1999$.

on turf grass. It is worthy to be noted that terbucarb is proved to be cytotoxic, and the mitochondrial respiratory system and protein thiols were important targets of terbucarb (Suzuki et al., 1997).

\subsubsection{Limitation analysis}

This preliminary screening procedure can be seen as the first step to identify OMs with potential risk. In particular, some emerging contaminants identified in this study, such as cashmeran and thymol (Tables S4 and S5), is of great concern (Bu et al., 2013b). Once the environmental occurrence of OMs is deduced by our method, much more work can be designed to assess their sources, environmental behavior, and toxicity for better understanding of potential ecological and health risks.

It is necessary to note that some OMs from our current database were reported in previous studies, but were absent in our positive identification list. In detail, Gao et al. (2009) reported the levels of some selected organophosphorous pesticides (i.e. dichlorvos, demeton, dimethodate, malathion, parathion and methyl parathion) in surface water of the Liaohe River watershed, while they were all negatively identified in our screening. Similar phenomenon is observed in the case of polychlorinated biphenyls (PCBs) (Zhang et al., 2010). No PCB congener was positively identified by the high throughout semi-quantification method in either surface water or sediments at investigated sites.

OM misidentification by our high throughout screening method may be caused by the decline in occurrence, high detection limit, or both. For example, the recent intervention to limit the application of certain OMs (e.g. PCBs) results in their declining occurrence at a global scale (Kong et al., 2014). Besides, the high throughout screening method usually acquire GC data in full scan mode, which could inevitably deteriorate both sensitivity and detection limit. Therefore the current method may result in false negatives, which are not fully evaluated at present. Consequently, we cannot conclude that all negatively identified OMs are not environmental contaminants. Critically, although the detection limit of the current method was higher than that of target analysis, this is compensated by the simple and fast analysis of the massive information acquired. As the instrumental science advances, higher sensitivity and lower detection limit could be expected, and the high throughout screening method will show more attractive perspectives.

\section{Conclusion}

This work evaluates the usefulness of qualitative data and reliability of semi-quantification data obtained from a high throughout screening method. We can conclude that (1) our results demonstrated the feasibility of using massive qualitative data from the high throughout screening to identify the similarity (or dissimilarity) of pollution sources at different locations for water phase, which could provide insights for source back tracking of water contamination; (2) tests of the accuracy indicated that the semi-quantification method performed well in the preliminary OM screening analysis. However, more work should be done to confirm the occurrence levels for the vast majority of newly identified OMs; and (3) we note that the high throughout screening method should be critically evaluated and if the results were explained in caution, this method provide a simple and fast tool for understanding the pollution characteristics and occurrence levels of OMs for environmental managers.

\section{Acknowledgements}

This study was co-funded by National Natural Science Foundation of China (Grant Nos. 21307068 and 51290283), National High Technology Research and Development Program of China (863 Program) (No. 2014AA06A506) and the Ministry of Water Resources' Special Funds for Scientific Research on Public Causes (No. 201201032). We thank Kai Liu (Tsinghua University) for the language editing and useful comments.

\section{Appendix A. Supplementary material}

Supplementary data associated with this article can be found, in the online version, at http://dx.doi.org/10.1016/j.chemosphere. 2015.07.013.

\section{References}

Bai, Y., Meng, W., Xu, J., Zhang, Y., Guo, C., Lv, J., Wan, J., 2014. Occurrence, distribution, environmental risk assessment and source apportionment of polycyclic aromatic hydrocarbons (PAHs) in water and sediments of the Liaohe River Basin, China. Bull. Environ. Contam. Tox. 93, 744-751.

Bu, Q., Wang, D., Wang, Z., 2013. Review of screening systems for prioritizing chemical substances. Crit. Rev. Environ. Sci. Technol. 43, 1011-1041.

Bu, Q., Wang, D., Wang, Z., Gu, J., 2014a. Identification and ranking of the risky organic contaminants in the source water of the Danjiangkou reservoir. Front Environ. Sci. Eng. 8, 42-53.

Bu, Q., Wang, D., Liu, X., Wang, Z., 2014b. A high throughout semi-quantification method for screening organic contaminants in river sediments. J. Environ. Manage. 143, 135-139.

Bu, Q., Wang, B., Huang, J., Deng, S., Yu, G., 2013. Pharmaceuticals and personal care products in the aquatic environment in China: a review. J. Hazard. Mater. 262, 189-211.

Bu, Q.W. Zhang, Z.H., Lu, S., He, F.P., 2009. Vertical distribution and environmenta significance of PAHs in soil profiles in Beijing, China. Environ. Geochem. Health 31, 119-131.

Duong, H.T., Kadokami, K., Pan, S., Matsuura, N., Nguyen, T.Q., 2014. Screening and analysis of 940 organic micro-pollutants in river sediments in Vietnam using an automated identification and quantification database system for GC-MS. Chemosphere 107, 462-472. 
Feron, V.J., Cassee, F.R., Groten, J.P., van Vliet, P.W., van Zorge, J.A., 2002 International issues on human health effects of exposure to chemical mixtures. Environ. Health Perspect. 110, 893-899.

Gómez, M.J., Gómez-Ramos, M.M., Agüera, A., Mezcua, M., Herrera, S., FernándezAlba, A.R., 2009. A new gas chromatography/mass spectrometry method for the simultaneous analysis of target and non-target organic contaminants in waters. J. Chromatogr. A 1216, 4071-4082.

Gao, J., Liu, L., Liu, X., Zhou, H., Lu, J., Huang, S., Wang, Z., 2009. The occurrence and spatial distribution of organophosphorous pesticides in Chinese surface water. Bull. Environ. Contam. Tox. 82, 223-229.

Gfrerer, M., Martens, D., Gawlik, B.M., Wenzl, T., Zhang, A., Quan, X., Sun, C., Chen, J., Platzer, B., Lankmayr, E., Kettrup, A., 2002. Triazines in the aquatic systems of the Eastern Chinese Rivers Liao-He and Yangtse. Chemosphere 47, 455-466.

Guo, W., He, M., Yang, Z., Lin, C., Quan, X., Wang, H., 2007. Distribution of polycyclic aromatic hydrocarbons in water, suspended particulate matter and sediment from Daliao River watershed, China. Chemosphere 68, 93-104.

Kadokami, K., Tanada, K., Taneda, K., Nakagawa, K., 2005. Novel gas chromatography-mass spectrometry database for automatic identification and quantification of micropollutants. J. Chromatogr. A 1089, 219-226.

Kadokami, K., Pan, S., Hanh, D.T., Li, X., Miyazaki, T., 2012. Development of a comprehensive analytical method for semi-volatile organic compounds in sediments by using an automated identification and quantification system with a GC-MS database. Anal. Sci. 28, 1183-1189.

Kadokami, K., Li, X., Pan, S., Ueda, N., Hamada, K., Jinya, D., Iwamura, T., 2013. Screening analysis of hundreds of sediment pollutants and evaluation of their effects on benthic organisms in Dokai Bay, Japan. Chemosphere 90, 721-728.

Kong, D., MacLeod, M., Hung, H., Cousins, I.T., 2014. Statistical analysis of long-term monitoring data for persistent organic pollutants in the atmosphere at 20 monitoring stations broadly indicates declining concentrations. Environ. Sci. Technol. 48, 12492-12499.

Long, E., Macdonald, D., Smith, S., Calder, F., 1995. Incidence of adverse biological effects within ranges of chemical concentrations in marine and estuarine sediments. Environ. Manage. 19, 81-97.

Pan, S., Kadokami, K., Li, X., Duong, H.T., Horiguchi, T., 2014. Target and screening analysis of 940 micro-pollutants in sediments in Tokyo Bay, Japan. Chemosphere 99, 109-116.

Qiao, M., Huang, S., Wang, Z., 2008. Partitioning characteristics of PAHs between sediment and water in a shallow lake. J. Soils Sediments 8, 69-73.
Quimby, B., Szelewski, M., 2006. Screening for hazardous chemicals in homeland security and environmental samples Using a GC/MS/ECD/FPD with a 731 compound DRS database. Agilent Technologies.

Schwarzenbach, R.P., Gschwend, P.M., Imboden, D.M., 2003. Environmental Organic Chemistry, second ed. Wiley, Hoboken, NJ, USA.

Schwarzenbach, R.P., Egli, T., Hofstetter, T.B., von Gunten, U., Wehrli, B., 2010. Global water pollution and human health. Annu. Rev. Environ. Resour. 35, 109-136.

Sharpe, R.M., 2001. Hormones and testis development and the possible adverse effects of environmental chemicals. Toxicol. Lett. 120, 221-232.

Sharpe, R.M., Irvine, D.S., 2004. How strong is the evidence of a link between environmental chemicals and adverse effects on human reproductive health? BMJ (Clin. Res. Ed.) 328, 447-451.

Suzuki, T., Yaguchi, K., Suga, T., Nakagawa, Y., 1997. Cytotoxic effects of 2,6-di-tertbutyl-4-methylphenyl N-methylcarbamate (terbutol) herbicide on hepatocytes and mitochondria isolated from male rats. Environ. Toxicol. Phar. 3, 167-173.

Wang, H., He, M., Lin, C., Quan, X., Guo, W., 2007. Distribution characteristics of organochlorine in river surface sediments in Song-Liao watershed. Chin. J. Appl. Ecol. 18, 1523-1527 (in Chinese).

Wylie, P.L., 2006. Screening for 926 pesticides and endocrine disruptors by GC/MS with deconvolution reporting software and a new pesticide library. Agilent Technologies.

Yan, D.-H., He, Y., Wang, H., 2005. Environmental characteristics of the atrazine in the waters in East Liaohe River Basin. Huanjing Kexue 26, 203-208 (in Chinese).

Zhang, H., Zhao, X., Ni, Y., Lu, X., Chen, J., Su, F., Zhao, L., Zhang, N., Zhang, X., 2010. PCDD/Fs and PCBs in sediments of the Liaohe River, China: levels, distribution, and possible sources. Chemosphere 79, 754-762.

Zhang, J.X., Ni, Y.W., Yang, M., Zhang, H.J., Zhang, Q., Chen, J.P., 2008. Characterization and distribution of PAHs in surface sediments of Daliao River, China. J. Environ. Sci. Health., Part A 43, 375-381.

Zhao, J-L., Zhang, O-O. Chen, F., Wang, L., Ying, G.-G., Liu, Y.-S., Yang, B., Zhou, L.-J., Liu, S., Su, H.-C., Zhang, R.-Q., 2013. Evaluation of triclosan and triclocarban at river basin scale using monitoring and modeling tools: implications for controlling of urban domestic sewage discharge. Water Res. 47, 395-405.

Zhong, W., Wang, D., Xu, X., Luo, Q., Wang, B., Shan, X., Wang, Z., 2010. Screening level ecological risk assessment for phenols in surface water of the Taihu Lake. Chemosphere 80, 998-1005. 